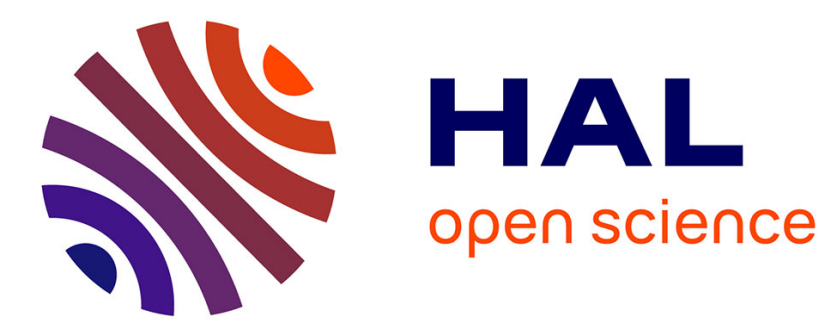

\title{
Maturation of a ketoprofen/beta-cyclodextrin mixture with supercritical carbon dioxide
}

Arezki Bounaceur, Élisabeth Rodier, Jacques Fages

\section{To cite this version:}

Arezki Bounaceur, Élisabeth Rodier, Jacques Fages. Maturation of a ketoprofen/beta-cyclodextrin mixture with supercritical carbon dioxide. Journal of Supercritical Fluids, 2007, 41 (3), p. 429-439. 10.1016/j.supflu.2006.11.004 . hal-01618300

\section{HAL Id: hal-01618300 https://hal.science/hal-01618300}

Submitted on 24 Nov 2017

HAL is a multi-disciplinary open access archive for the deposit and dissemination of scientific research documents, whether they are published or not. The documents may come from teaching and research institutions in France or abroad, or from public or private research centers.
L'archive ouverte pluridisciplinaire HAL, est destinée au dépôt et à la diffusion de documents scientifiques de niveau recherche, publiés ou non, émanant des établissements d'enseignement et de recherche français ou étrangers, des laboratoires publics ou privés. 


\title{
Maturation of a ketoprofen/ $\beta$-cyclodextrin mixture with supercritical carbon dioxide
}

\author{
Arezki Bounaceur, Elisabeth Rodier*, Jacques Fages \\ Ecole des Mines d'Albi, RAPSODEE Research Center, UMR EMAC-CNRS 2392, 81013 Albi, France
}

\begin{abstract}
This work studies the maturation process of an association complex between an active compound, ketoprofen (KP) and a $\beta$-cyclodextrin (CD) with supercritical carbon dioxide $\left(\mathrm{SC}-\mathrm{CO}_{2}\right)$. The process involves putting these two compounds into contact with a certain quantity of water, over a certain duration, to obtain the complex. We have studied the phenomena involved and the influence of several operating parameters on the complexation rate. The results enable us to suggest explanations for the phenomena involved in inclusion formation. An increase in the parameters related to the process: pressure, temperature, maturation period, agitation and density of $\mathrm{SC}-\mathrm{CO}_{2}$ resulted in an increase in the association rate of $\mathrm{KP}$ with $\mathrm{CD}$ in all cases. The water added at the end of the mixing procedure allowed a surface solubilization of $\mathrm{CD}$ where a ripening phenomenon can occur, but it is also a destabilizing agent for the water already adsorbed on the $\mathrm{CD}$. The added water then favours an evolution towards a more stable energy state by enhancing the emptying of the CD cavities, and being replaced by KP. The mass ratio of the $\mathrm{SC}-\mathrm{CO}_{2} / \mathrm{mixture}$ had an effect on association, as the use of great volumes of $\mathrm{CO}_{2}$ caused dilution of $\mathrm{KP}$ and was deleterious to the complexation rate. It was also found that the method of mixture preparation influenced the formation of the complex: adding water before KP onto CD inhibited complexation. The stoichiometry of complexation was found to be one molecule of KP with two molecules of $\mathrm{CD}$. With control of both the operating conditions (pressure, temperature, maturation period, agitation and density of $\mathrm{SC}-\mathrm{CO}_{2}$ ) and the preparation of the mixing, this process leads to high percentages of complexation without the use of organic solvent.
\end{abstract}

Keywords: Supercritical carbon dioxide; Ketoprofen; Beta-cyclodextrin; Supercritical maturation process; Association complex

\section{Introduction}

Active substances produced and used in the pharmaceutical field, such as ketoprofen (KP), are not very polar and thus have low water solubility. In spite of their therapeutic effectiveness, this low solubility hinders their use [1-3]. To increase their rate of dissolution, such compounds can be coated with a water-soluble layer and included in or associated to cage compounds, such as cyclodextrins (CDs) leading to the formation of a complex.

Abbreviations: AC, active compound; CD, cyclodextrin; DMSO, dimethyl sulfoxide; DSC, differential scanning calorimetry; KP, ketoprofen; NSAID, non-steroidal anti-inflammatory drug; PGSS, particle from gas-saturated suspension/solution; RESS, rapid expansion of supercritical solution; SAS, supercritical anti-solvent; $\mathrm{SC}-\mathrm{CO}_{2}$, supercritical carbon dioxide

* Corresponding author. Tel.: +33 5634931 53; fax: +33 563493025

E-mail address: rodier@enstimac.fr (E. Rodier).
In addition to the classical ways of obtaining association complexes from an aqueous medium or by kneading or grinding, the use of supercritical fluids has recently been investigated [1]. Among processes performed in aqueous media, there is atomization, freeze-drying and CD crystallization [4,5]. Forming complexes in aqueous media often leads to a product containing traces of solvent with the particles having relatively large mean size and broad size distributions.

The use of supercritical fluids offers new methods for increasing the rate of dissolution of drugs that are hydrophobic. Carbon dioxide $\left(\mathrm{CO}_{2}\right)$ is the most widely used supercritical fluid because of its relatively low cost, lack of toxicity and easily obtainable supercritical conditions. The solid complexes formed in supercritical medium are commonly highly pure, with a small mean particle size and a narrow particle size distribution [6].

Several processes using supercritical fluids for the formation of fine particles have already been developed. They are based on the solvent and low viscosity properties of supercritical fluids. The main processes used in supercritical medium are: the 


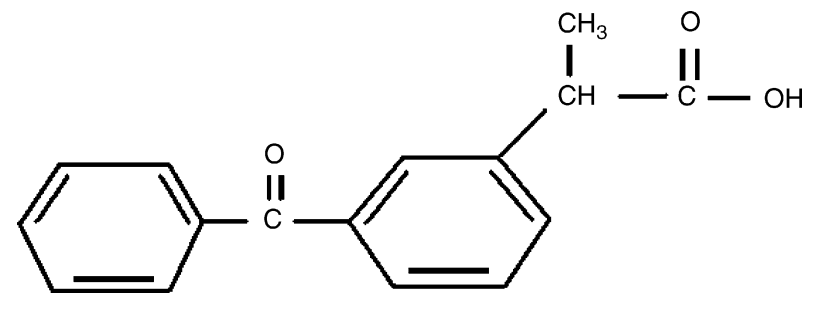

Fig. 1. Schematic structure of ketoprofen.

RESS Process (Rapid Expansion of Supercritical Solution), the SAS Process (Supercritical Antisolvent) and the PGSS ${ }^{\circledR}$ Process (Particle from Gas-Saturated Solution) [7-10].

Up to date, three supercritical processes have been proposed to form an association complex. In the first process, a drug dissolved into supercritical carbon dioxide $\left(\mathrm{SC}-\mathrm{CO}_{2}\right)$ can be percolated through a bed of $\mathrm{CD}$ [3]. In the second process, a solution of a drug and a $\mathrm{CD}$ dissolved into an organic solvent can be co-injected with $\mathrm{SC}-\mathrm{CO}_{2}$ and a co-crystallization then occurs due to the anti-solvent effect of $\mathrm{SC}-\mathrm{CO}_{2}$ [11]. In the third process, the active substance, the $\mathrm{CD}$ and some water are held in contact in supercritical medium over a certain period. This last process is the supercritical maturation process first developed by a team from Liège University [1]. Previous work using this method involved the association of a non-steroidal anti-inflammatory drug (NSAID), Piroxicam [1], anti-fungal, Miconazole and conservatives, and Parabens [2]. The study was continued to understand the role played by the addition of an acid ternary agent (malic, maleic, fumaric and citric acid) on the inclusion of Miconazole in the various types of CDs [12]. Marongiu et al. [13] used the same procedure to form an association complex of Imazalil/beta-CD. In the same year, our laboratory studied the association of Eflucimibe and $\gamma$-CD [14]. Although this process proved to be effective, the phenomena implied are far from being understood.

KP belongs to the class of NSAID (non-steroidal antiinflammatory drug), derived from arylpropionic acid. It has an activity in the treatment of inflammatory rheumatoid diseases and for the relief of acute pain. It is effective against period pains, pain after surgery, and fever. Its chemical formula is $\mathrm{C}_{16} \mathrm{H}_{14} \mathrm{O}_{3}$ (2-( $m$-benzoylphenyl) propionic acid) having a molecular weight of $254.28 \mathrm{~g} \mathrm{~mol}^{-1}$, a melting point of $368.2 \mathrm{~K}$ with the chemical structure being in shown Fig. 1.

CDs are a family of cyclic oligosaccharides that are derived from the enzymatic hydrolysis of starch by CD glucanotransferase enzyme (CGTase) [15,16]. According to the genus of the bacterium (Bacillus) producing this enzyme as well as the operating conditions, the product of hydrolysis contains a variable ratio of three natural CDs including 6,7 or 8 glycosyl units. They are respectively called $\alpha-, \beta$ - and $\gamma$-CDs. The schematic structure of $\beta$-CDs is shown on Fig. 2. CD molecules have the form of a slightly truncated cone, with a hydrophilic external part and a hydrophobic cavity. The hydroxyl groups in these molecules are located on each face of the ring, while the cavity contains the glucosidic groups. CDs are able to form inclusion complexes with several organic molecules and or part of them based on interac-

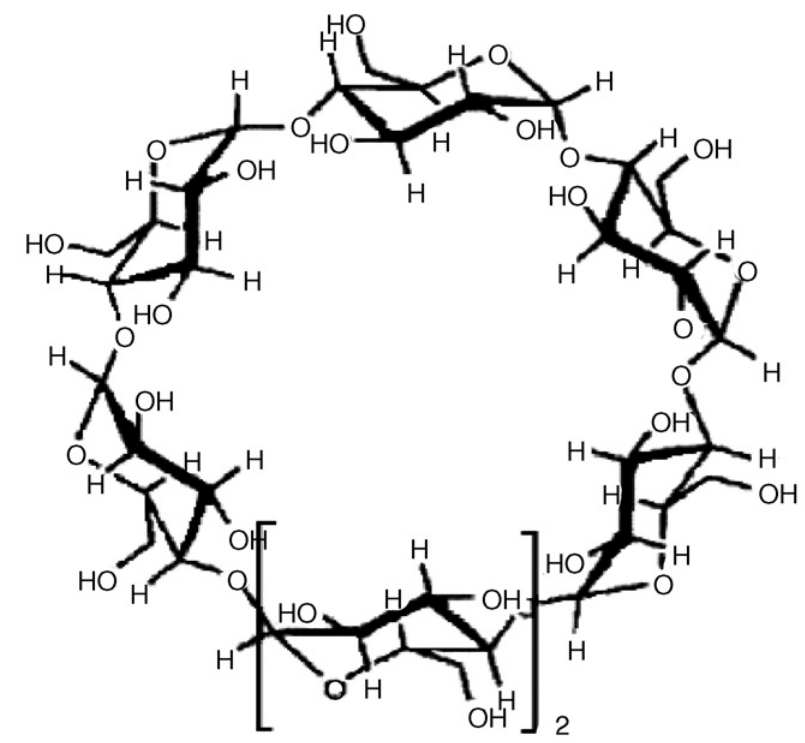

Fig. 2. Schematic structure of $\beta$-cyclodextrin.

tions using physico-chemical, non-covalent forces such as van der Waals forces and hydrophobic interactions. The resulting complex may improve the solubility, stability and bioavailability of the guest molecules [17-19].

Our work is trying to clarify the interaction mechanisms between $\beta-\mathrm{CD}$, ketoprofen and $\mathrm{SC}-\mathrm{CO}_{2}$ involved in the complexation using the supercritical maturation process. In order to achieve this, we study the influence of the process parameters, namely, pressure, temperature, maturation period, density of $\mathrm{SC}-\mathrm{CO}_{2}$ and agitation and those related to the physical mixture composition like amount of water, mole ration $\mathrm{KP} / \beta-\mathrm{CD}$ and mass ratio $\mathrm{SC}-\mathrm{CO}_{2} /$ mixture and finally the method of preparation of the mixture.

\section{Experimental set-up, materials and methods}

\subsection{The experimental set-up}

Maturation tests were carried out in a multifunction pilot plant (Separex, France). Fig. 3 presents the configuration of the plant for maturation. $\mathrm{CO}_{2}$ is initially stored in liquid form at $5 \mathrm{MPa}$ and $273.2 \mathrm{~K}$ in reservoir (2). Liquid $\mathrm{CO}_{2}$ is then pumped by the membrane pump (3), to be pressurized up to $35 \mathrm{MPa}$. By cooling the head of the pump, it is possible to maintain the fluid in the liquid state and avoid cavitation. Compressed $\mathrm{CO}_{2}$ then passes through a heat exchanger (4) to become supercritical. The mass flow of $\mathrm{CO}_{2}$ was fixed at $20 \mathrm{~kg} / \mathrm{h}$. The autoclave (5) with a capacity of $2 \mathrm{~L}$ was electrically heated and contained the mixture to be maturated. Indicators of $\mathrm{CO}_{2}$ flow, pressure and temperature, on the control panel gave direct readings of these process parameters.

We carried out some maturation tests using a Labsize pilot unit, also built by Separex, to determine the effect of agitation and of the mass ratio $\mathrm{SC}-\mathrm{CO}_{2} /$ mixture on the complexation process. The Labsize pilot unit was similar to the main pilot, but 


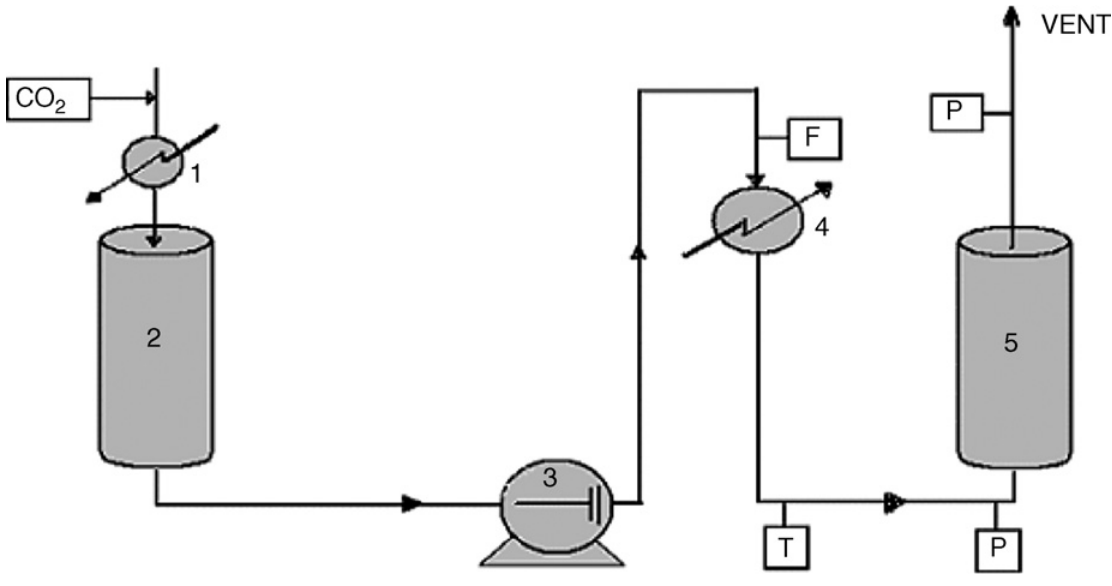

Fig. 3. Experimental set-up (1: condenser, 2: liquid $\mathrm{CO}_{2}$ tank, 3: membrane pump, 4: heat exchanger, 5: autoclave for maturation, F: flowmeter, P: manometer, T: thermometer).

the maturation autoclave had a capacity of only $0.5 \mathrm{~L}$ and was equipped with a mechanical stirrer.

\subsection{Operating mode}

To perform complexation in the supercritical medium, we first prepared a physical mixture of the components. This involved manually mixing with a spatula, a given quantity of KP, $\beta-\mathrm{CD}$ and water. The size of the mixture varied between 7 and $22 \mathrm{~g}$. This mixture denoted as the "physical mixture" was placed in a basket closed by two sintered steel porous plates, which was then placed in the maturation autoclave (5). $\mathrm{CO}_{2}$ flowed in, until the desired pressure and the temperature was reached. The autoclave was isolated for the duration of maturation. At the end of the experiment, the apparatus was depressurized by sending SC$\mathrm{CO}_{2}$ to the vent.

\subsection{Materials}

Four different substances, $\mathrm{CO}_{2}, \mathrm{KP}, \beta-\mathrm{CD}$ and water were used in the experiments. $\mathrm{CO}_{2}$ (purity $99.995 \%$ ) was supplied by Air Liquide SA, France. The active compound (KP) was supplied by Boehringer-Ingelheim, Germany. We roughly evaluated the solubility of $\mathrm{KP}$ in $\mathrm{SC}-\mathrm{CO}_{2}$ in the autoclave of $2 \mathrm{~L}$ of the pilot plant. The test was carried out without agitation during $4 \mathrm{~h}$. The initial quantity of the $\mathrm{KP}$ in the autoclave is $4 \mathrm{~g}$ and the total quantity dissolved in the $\mathrm{SC}-\mathrm{CO}_{2}$ after $4 \mathrm{~h}$ is $0.3 \mathrm{~g}$. It was found that, at $20 \mathrm{MPa}$ and $338 \mathrm{~K}$ corresponding to a $\mathrm{CO}_{2}$ density of $0.661 \mathrm{~kg} / \mathrm{m}^{3}$, the solubility of $\mathrm{KP}$ is $0.15 \mathrm{~g} / \mathrm{L}$ $\left(y_{\mathrm{KP}}=4.1 \times 10^{-5}\right)$. According to the literature, at $22 \mathrm{MPa}$ and $331.5 \mathrm{~K}$, the molar fraction of $\mathrm{KP}$ in $\mathrm{CO}_{2}$ is $y_{\mathrm{KP}}=15.5 \times 10^{-5}$ and at $10 \mathrm{MPa}$ and $312.5 \mathrm{~K} y_{\mathrm{KP}}=1.33 \times 10^{-5}$ [20]. In addition, KP is not very water-soluble with its solubility, at $298.2 \mathrm{~K}$ being given as $0.13 \mathrm{~g} / \mathrm{L}$ [21]. The $\beta-\mathrm{CD}$ Cavamax W7 Pharma was provided by Wacker. $\beta-\mathrm{CD}$ is almost insoluble in $\mathrm{SC}-\mathrm{CO}_{2}$ [14,22].

In comparison with other natural CDs, $\beta-\mathrm{CD}$ is the least water-soluble. At $293.2 \mathrm{~K}$ and atmospheric pressure, the water solubility of $\beta-\mathrm{CD}$ is $16.4 \mathrm{~g} / \mathrm{L}$ and it reaches $18.5 \mathrm{~g} / \mathrm{L}$ at $298.2 \mathrm{~K}$ and $196.6 \mathrm{~g} / \mathrm{L}$ at $353.2 \mathrm{~K}[15,23]$. Distilled water was used. Stahl et al. [24] presents the variation of the solubility of water at $320.2 \mathrm{~K}$ in $\mathrm{CO}_{2}$ for various pressures. This data was then converted to saturation concentration of water in $\mathrm{CO}_{2}$ as function of $\mathrm{CO}_{2}$ density. The density of $\mathrm{CO}_{2}$ was determined by the Peng-Robinson equation of state [25]. The results are given in Fig. 4 where solubility is in $\mathrm{g}_{\text {water }} / \mathrm{L}_{\mathrm{CO}_{2}}$ and density in $\mathrm{kg} / \mathrm{m}_{\mathrm{CO}_{2}}^{3}$.

\subsection{Analytical methods}

\subsubsection{Differential scanning calorimetry (DSC)}

The DSC allows the determination of the percentage of complexed or amorphized active compound [26]. A Perkin-Elmer DSC-7 was used to measure the heat absorbed by the sample when non-complexed crystalline active compound melts by increasing the temperature from 293.2 to $393.2 \mathrm{~K}$ at $2 \mathrm{~K} / \mathrm{min}$, under nitrogen flow. The sample sizes were $4.5-5 \mathrm{mg}$. The comparison of the thermogram corresponding to the fusion of non-included or free KP with that of pure KP enables us to calculate the percentage of inclusion.

To determine the percentage of inclusion of KP in $\mathrm{CD}$, we have used the Eq. (1):

$\% \mathrm{AC}$ complexed $=1-\frac{\left(\Delta H_{\mathrm{f} 1} / \Delta H_{\mathrm{f} 2}\right)}{\left(M_{1} / M_{2}\right)}$

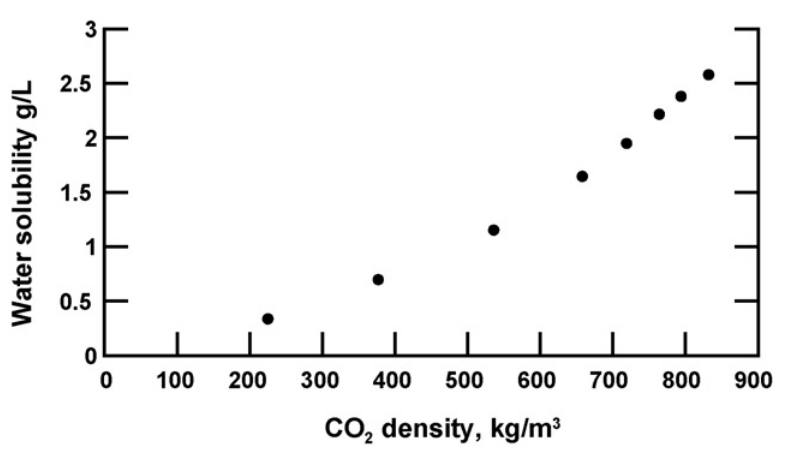

Fig. 4. Variation of the solubility of water in $\mathrm{SC}-\mathrm{CO}_{2}$ for various densities at 323.15 K [20]. 


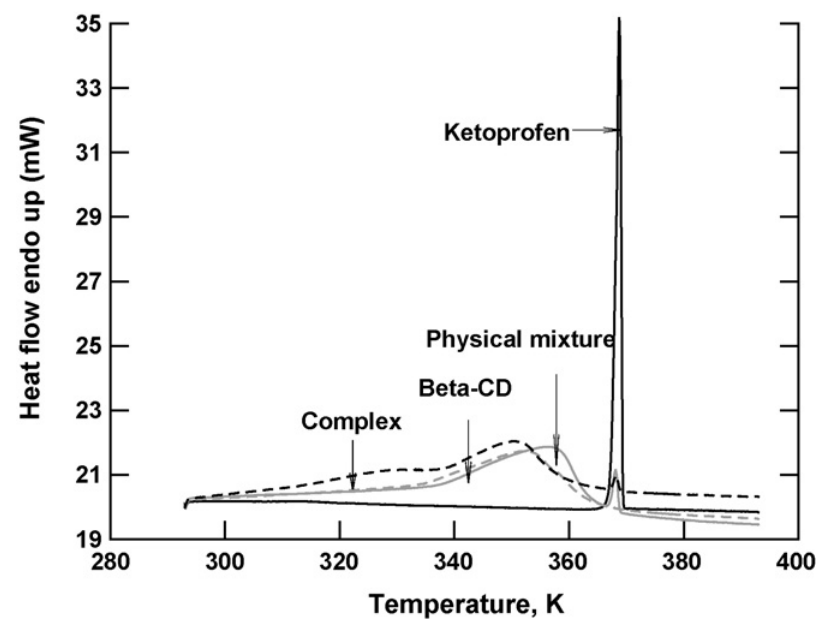

Fig. 5. Differential scanning calorimetry thermograms of ketoprofen, $\beta$ cyclodextrin, physical mixture and complex.

$\% \mathrm{AC}$ complexed is the mass percentage of the complexed active compound (KP), $\Delta H_{\mathrm{f} 1}$ the enthalpy of fusion of non-included $\mathrm{KP}$ after complexation $(\mathrm{J} / \mathrm{g}), \Delta H_{\mathrm{f} 2}$ the enthalpy of fusion of pure $\mathrm{KP}(\mathrm{J} / \mathrm{g}), M_{1}$ initial mass of KP contained in the physical mixture (g) before maturation, $M_{2}$ is the mass of physical mixture $(\mathrm{g})$ before maturation. Examples of DSC curves of pure KP, $\beta-\mathrm{CD}$, physical mixture and complex are given on Fig. 5. We decided to analyze by X-ray diffractometry the KP behaviour in order to see if it might be amorphized when processed. In this way, we could see if the percentage of non-crystalline $\mathrm{AC}$ is only complexed powder or a mixture of amorphized and complexed AC.

The thermal characterization method for complexation compounds is now a standard method as confirmed in the review by Giordano et al. [27] but this method has to be completed by other characterization methods such as $\mathrm{X}$-ray diffraction analyzing crystallinity or the differential solubility method quantifying the complexation amount of active compound [2].

\subsubsection{Environmental scanning electronic microscope}

The samples of KP, $\beta-\mathrm{CD}$, physical mixture and complex were observed using an environmental scanning electronic microscope XL30 ESEM FEG (Philips, Netherlands). The microscope pictures of $\mathrm{KP}, \beta-\mathrm{CD}$, physical mixture and complex are shown in Fig. 6 . The KP particles are crystals with a mean volume diameter of $5.15 \mu \mathrm{m}$. The $\beta$-CDs particles were larger than those of KP and had a mean volume diameter of $34.84 \mu \mathrm{m}$. These mean volume diameters were determined by using the Malvern Mastersizer 2000 laser diffraction instrument. Concerning the physical mixture, it may be noted that the KP particles were deposited onto the CD. The CDs particles present cracks caused by the added water molecules, which solubilized partially their surfaces. The complex seemed more homogeneous than the physical mixture.

\subsubsection{Karl Fisher coulometer}

We measured the mass percentage of water in $\beta-\mathrm{CD}$, physical mixture and complex using a Karl Fisher DL37 coulometer. The water was quantified by an electrochemical reaction with iodine.
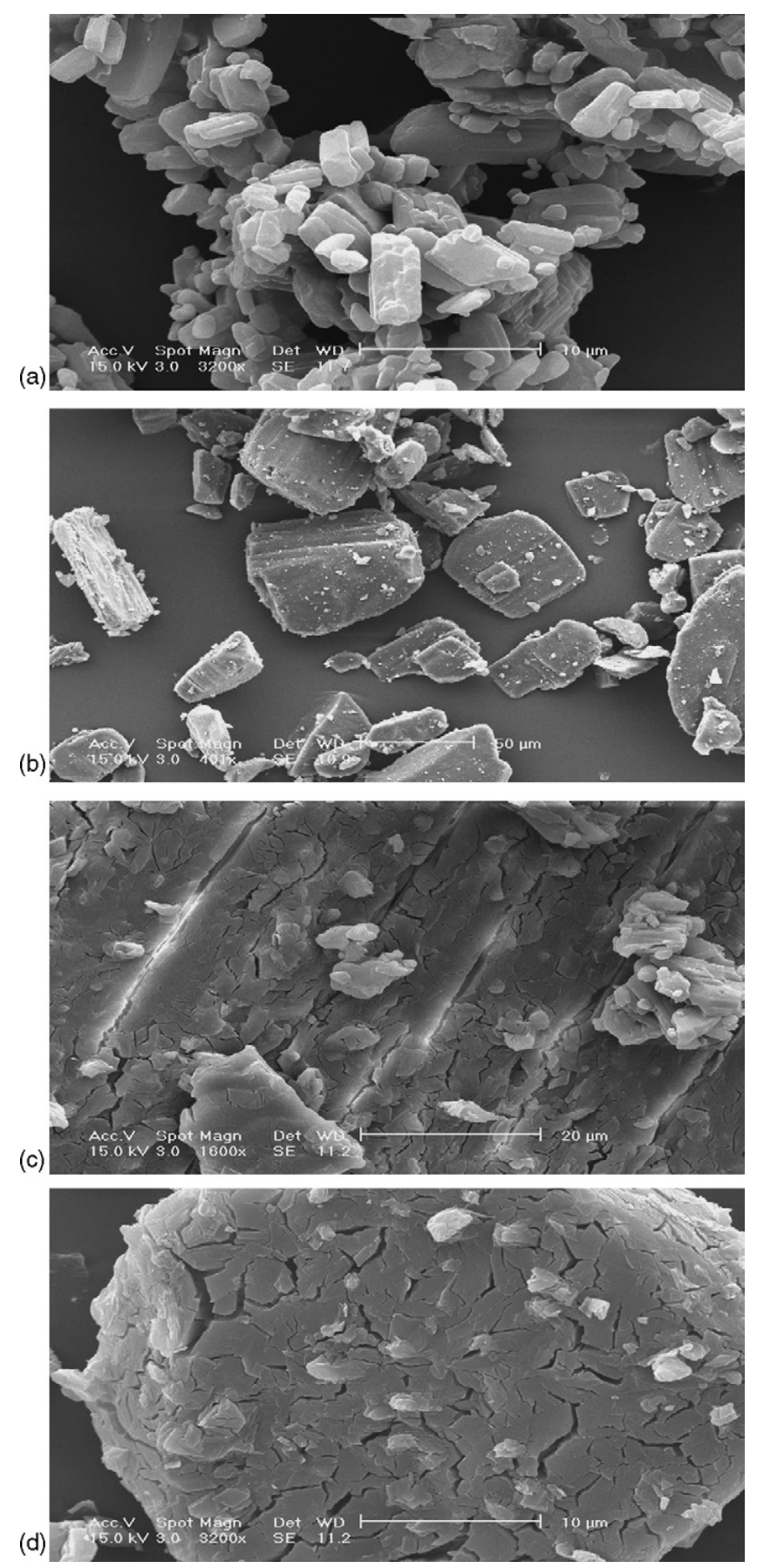

Fig. 6. SEM pictures of ketoprofen (a), $\beta$-cyclodextrin (b), wetted physical mixture (c) and complex (d).

The current generated by this reaction gives a measure of the amount of water. For this, the powder had to be dissolved and the solvent used here was DMSO (dimethylsulfoxide), it was supplied by Aldrich (purity 99.9\%).

\subsubsection{X-ray diffractometry}

$X$-ray measurements were performed on a diffractometer (Philips, $\mathrm{X}^{\prime}$ Pert), from $10^{\circ}$ to $40^{\circ}$, with a step of $0.017^{\circ}$. The 
source of the diffractometer is a copper tube and the detector is $\mathrm{X}^{\prime}$ cellerator.

\section{Experiments: process parameters and results}

\subsection{Process parameters}

Complexation in a supercritical medium requires first the preparation of the physical mixture. The quantities of KP, $\beta$ $\mathrm{CD}$ and water, as well as the mole ratio $\mathrm{KP} / \beta-\mathrm{CD}$ for each type of mixture, are presented in Table 1 . The reference mixture is mixture 1.

The parameters varied were:

- Process parameters: pressure, temperature, duration of maturation, density of $\mathrm{SC}-\mathrm{CO}_{2}$ and agitation.

- Composition mixture parameters: amount of water, mole ratio $\mathrm{KP} / \beta-\mathrm{CD}$, mass ratio $\mathrm{SC}-\mathrm{CO}_{2} /$ mixture.

- Method of preparation of the physical mixture: water added to the $\mathrm{KP} / \beta-\mathrm{CD}$ mixture, water added to $\beta-\mathrm{CD}$ before addition of KP.

\subsection{Main results and effects of the tested parameters}

To introduce the results, a discussion about the nature of the processed powder is necessary. Fig. 7 presents the $\mathrm{X}$-ray diffractograms of complexed powder, or amorphized KP and/or CD powders. To know whether water could induce a change in crystallinity of the KP, we put water into contact with KP and then dried and analyzed the powder. Diffractograms of untreated KP and wetted ones were found to be identical (Fig. 7a). We also compared the diffractograms of the physical mixture and of the $\mathrm{CD}$ alone (Fig. 7b). It can be seen that $\mathrm{CD}$ was not amorphized. As for KP, a lot of peaks were common to both compounds, yet a few of them could be distinguished that are relevant to KP (at $17.32^{\circ}$ and $15.96^{\circ}$ ). Hence, KP has not been amorphized in the physical mixture. Mura et al. [28] processed some KP/ $\beta$ CD physical mixtures in different ways, by grinding, kneading, sealed-heating, co-lyophilizing; and adding some water for some of these processes. They analyzed the obtained mixtures and found that peaks relevant to KP were detectable in all the systems, except in co-lyophilized products. We concluded that the decrease of KP fusion peak on DSC thermogramms was due to complexation and not to amorphization. We could not prove that the compound was an inclusion complex and hence, we
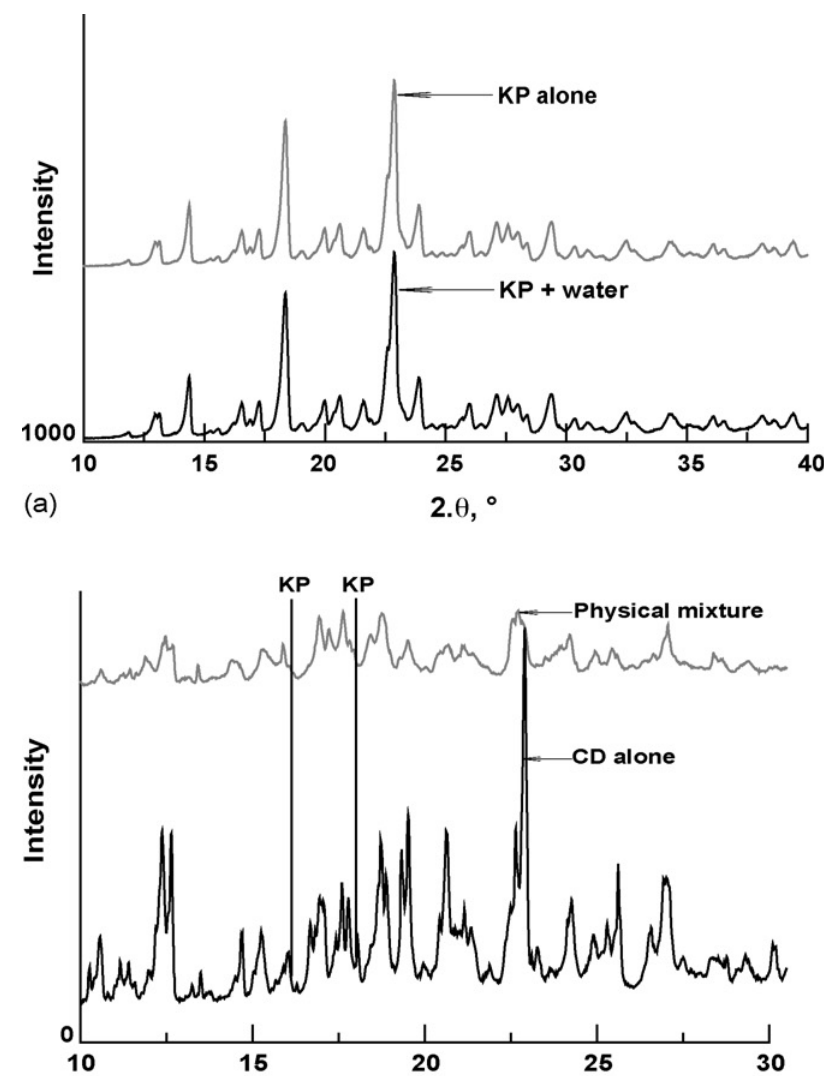

(b)

2. $\theta^{\circ}$

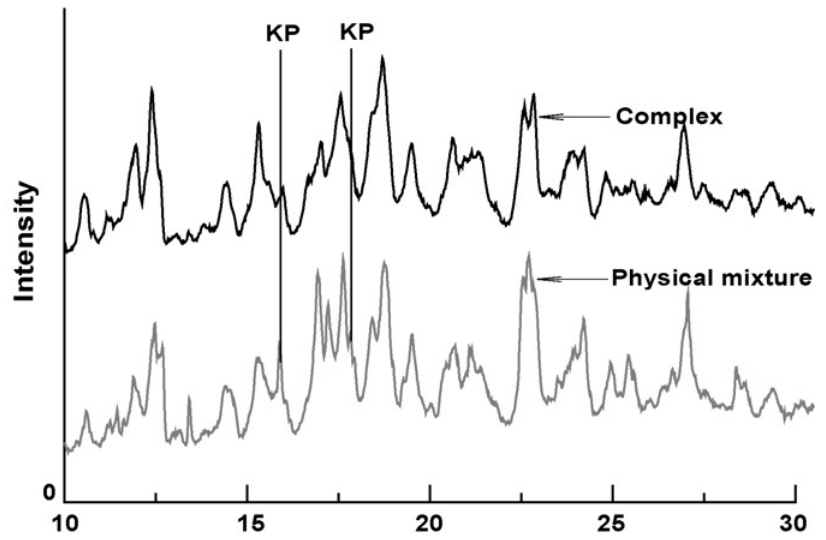

(c)

2. $\theta,^{\circ}$

Fig. 7. X-ray diffractograms of wetted KP and untreated one (a), of CD and physical mixture (b) and of complexed powder and physical mixture.

Table 1

Compositions of the physical mixtures

\begin{tabular}{|c|c|c|c|c|c|c|c|c|}
\hline Physical mixture & 1 & 2 & 3 & 4 & 5 & 6 & 7 & 8 \\
\hline Total mass of the mixture & 7 & 7 & 7 & 7 & 7 & 7 & 22 & 15 \\
\hline Molar ratio $\mathrm{KP} / \beta-\mathrm{CD}$ & 0.5 & 0.5 & 0.5 & 1 & 0.4 & 0.75 & 0.5 & 0.5 \\
\hline Mass fraction of total water & 0.15 & 0.25 & 0.908 & 0.15 & 0.15 & 0.15 & 0.15 & 0.15 \\
\hline Mass of $\beta-C D(g)$ & 5.351 & 4.721 & 5.723 & 4.86 & 5.644 & 5.09 & 16.816 & 11.465 \\
\hline Mass of water in $\beta-C D(g)$ & 0.675 & 0.524 & 0.636 & 0.54 & 0.711 & 0.64 & 2.121 & 1.445 \\
\hline Mass of added water $(\mathrm{g})$ & 0.375 & 1.227 & 0 & 0.51 & 0.339 & 0.41 & 1.183 & 0.805 \\
\hline Mass of ketoprofen (g) & 0.599 & 0.528 & 0.641 & 1.09 & 0.506 & 0.855 & 1.88 & 1.284 \\
\hline
\end{tabular}




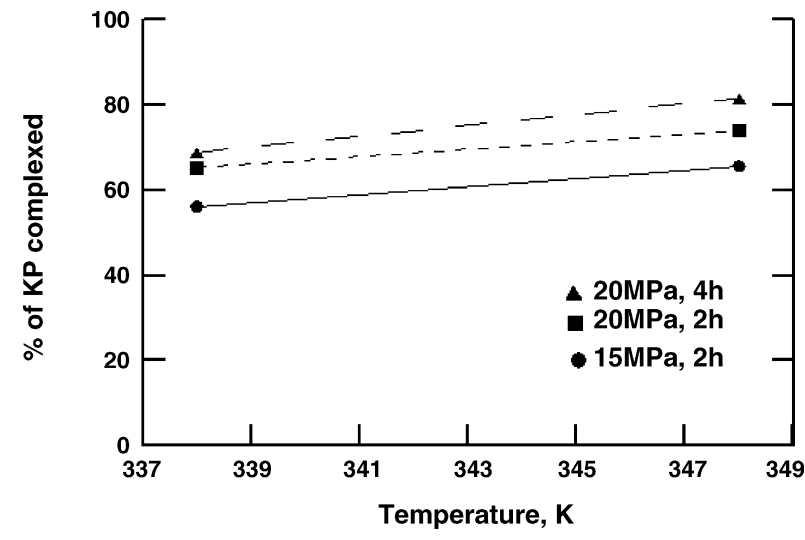

Fig. 8. Percentage of complexed KP according to temperature at fixed pressures.

will denote the compound as an association complex. In addition, comparison of the processed powder and of the physical mixture (Fig. 7c) shows that $\mathrm{CD}$ was not amorphized during the maturation process and the peaks relevant to KP were attenuated, due to its association to $\mathrm{CD}$.

\subsubsection{Reproducibility}

For the same complex, obtained at $15 \mathrm{MPa}$ and $338.2 \mathrm{~K}$ and $2 \mathrm{~h}$ of maturation with the mixture 1, we made three DSC analyses of three different samples. The standard deviation, defined here as the ratio of the mean deviation from the mean value to the mean value, on the measured heat of fusion was $0.7 \%$. This means that the complexation of KP with CDs can be considered to be homogeneous in the entire complexed mixture. Three experiments were also performed on the mixture 1 , at $15 \mathrm{MPa}$, $338.2 \mathrm{~K}$ and $2 \mathrm{~h}$ of maturation. The standard deviation on the measured heat of fusion was $0.9 \%$. The process, therefore, had satisfactory reproducibility.

\subsubsection{Effects of the operating variables}

3.2.2.1. Temperature. It was found that increasing temperature enhanced complexation rate (Fig. 8). This effect can be explained by observing the increase in temperature accelerated the kinetics of formation of the complex. Yet, the temperature had a negative effect on the solubility of the KP in the $\mathrm{SC}-\mathrm{CO}_{2}$ below $15 \mathrm{MPa}$, which is the crossover point of the solubility behaviour. Hence, if $\mathrm{SC}-\mathrm{CO}_{2}$ is a transfer medium for water and $\mathrm{KP}$; it is less efficient when increasing the temperature below $15 \mathrm{MPa}$. However, the enhancing effect of the temperature on complexation kinetics may prevail. Above $15 \mathrm{MPa}$, both complexation kinetics and KP solubility increased with temperature and thus the trend cannot be pointed out.

3.2.2.2. Maturation period. Increasing the contact time between $\mathrm{SC}-\mathrm{CO}_{2}$ and the physical mixture has a favourable effect on the complexation rate (see Fig. 9). Indeed, for $1.5 \mathrm{~h}$ maturation, the complexation was $47.6 \%$ and this reached $65.2 \%$ after $2 \mathrm{~h}$, and $75.2 \%$ after $5 \mathrm{~h}$. In other words, time of contact had a very important effect on complexation up to $2 \mathrm{~h}$ of maturation and becomes less significant for longer durations. This behaviour seems to be identical to a classical chemical equilib-

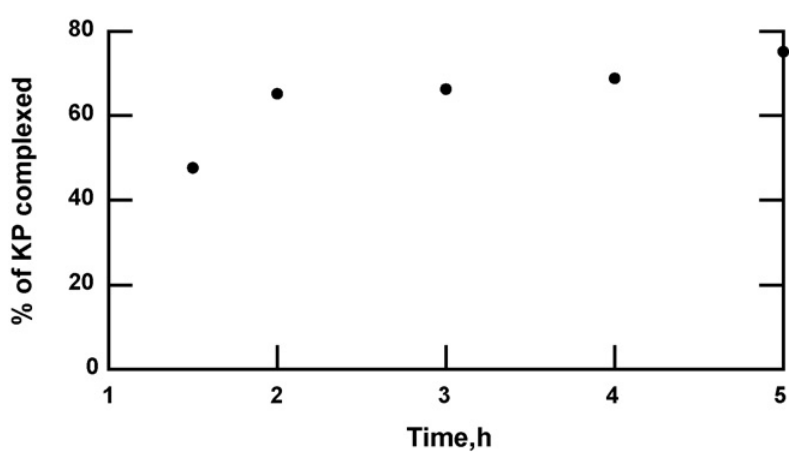

Fig. 9. Evolution of the amount of complexed KP with the duration of maturation (water added after ketoprofen).

rium reaction in which the reagents quantities decrease and the reaction rate of the complexation equilibrium slows down, as time proceeds.

3.2.2.3. Density of $\mathrm{SC}-\mathrm{CO}_{2}$. Increasing the density of $\mathrm{SC}-\mathrm{CO}_{2}$ enhanced complexation (see Fig. 10). SC-CO $\mathrm{CO}_{2}$ densities lead to larger quantities of both water and solubilized KP. Consequently, the transfer of KP and water towards the $\beta$-CDs, were enhanced via $\mathrm{CO}_{2}$ medium since there was probably more opportunities for contact between $\beta-C D$, water and KP. An enhancement effect of pressure on complexation, at a given temperature is also shown on Fig. 10.

3.2.2.4. Agitation. We carried out two tests on the Labsize pilot. The first test was made without agitation and gave a percentage of complexation of $60.2 \%$, while the second test made with mechanical agitation gave a percentage of complexation of $72.6 \%$. Thus, there was an increase in complexation of $12.3 \%$ when the mixture was stirred. The agitation speed was arbitrarily fixed at $350 \mathrm{rpm}$, which was an intermediate value within the stirrer operating range. Agitation increased the transfer of KP and water in $\mathrm{CO}_{2}$, as well as the transfer of $\mathrm{KP}$ in the mixture, thus a more homogeneous mixture was probably obtained.

\subsubsection{Effects of the mixture composition}

3.2.3.1. Amount of water. It should be noted that the addition of water is necessary for complexation to occur (Table 2). With a physical mixture prepared without any additional water thus

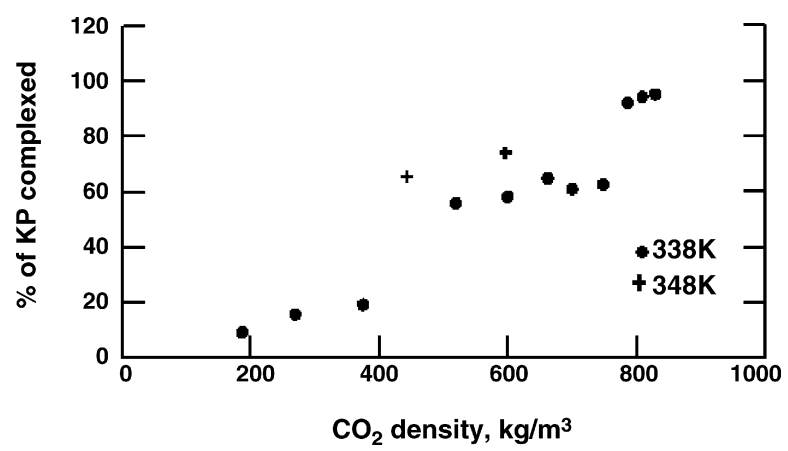

Fig. 10. Evolution of the amount of complexed $\mathrm{KP}$ with the density of $\mathrm{CO}_{2}$ at fixed temperatures. 
Table 2

\begin{tabular}{lll} 
Importance of water addition & & \\
\hline Fixed operating conditions & $\begin{array}{l}\text { Variation of the \% of } \\
\text { water in the physical } \\
\text { mixture }\end{array}$ & $\% \mathrm{KP}$ complexed \\
& 11.2 & 0 \\
\hline $\begin{array}{l}\text { Maturation at } 338.2 \mathrm{~K}, \\
15 \mathrm{MPa} \text {, during } 2 \mathrm{~h} \text { and a } \\
\text { molar ratio KP/ } \beta-\mathrm{CD}=1: 2\end{array}$ & 15 & 56.2 \\
& 25 & 95.4
\end{tabular}

Table 3

Effect of the molar ratio $\mathrm{KP} / \beta-\mathrm{CD}$ on inclusion

\begin{tabular}{lll}
\hline Fixed operating conditions & $\begin{array}{l}\text { Variation of the mole } \\
\text { ratio KP/ } / \mathrm{CD}\end{array}$ & \% KP complexed \\
\hline $\begin{array}{l}\text { Maturation at 348.2 K, } \\
20 \mathrm{MPa} \text {, during 2 } \mathrm{h}\end{array}$ & $1: 1$ & 30.8 \\
& $1: 1.33$ & 41.3 \\
& $1: 2$ & 74 \\
& $1: 2.5$ & 74.8 \\
\hline
\end{tabular}

with just the water adsorbed on initial $\beta-C D$, that is $11.2 \%$ of CD mass, we obtained no complexation and for $25 \%$ of total water content, where $\mathrm{SC}-\mathrm{CO}_{2}$ was potentially water-saturated, we obtained more than $95 \%$ complexation. The water added to the physical mixture probably partially solubilized the surface of $\beta$-CDs and caused crack to form, thus increasing their contact surface. The added water also destabilized the water initially present in the cavities of CDs. This internal water may become unstable with a higher energy state. The thermodynamic changes occurring during maturation will tend to restabilize the system. This could probably be achieved when the destabilized water leaves the CD cavities to allow access by the KP molecules. The included KP molecules in the cavities of CDs form then hydrophobic links with the glucosidic groups of CDs.

3.2.3.2. Molar ratio $K P / \beta-C D$. We determined the stoichiometry of complexation of KP in $\beta-C D$ and the results of the study are represented on Table 3. For the mole ratio KP/CD (1:1), the percentage of complexation was $30.8 \%$, and rose to $74 \%$ for a ratio 1:2 and then showed no additional variation for a ratio $1: 2.5$. Thus the stoichiometry of complexation of KP into $\beta-\mathrm{CD}$ was $1: 2$, i.e. a KP molecule was included in two molecules of CDs.

3.2.3.3. Mass ratio $\mathrm{SC}-\mathrm{CO}_{2}$ /mixture. To study the influence of the mass ratio, $\mathrm{SC}-\mathrm{CO}_{2} /$ mixture, we did maturation tests with
Table 4

Effect of mass ratio $\mathrm{SC}-\mathrm{CO}_{2} /$ physical mixture on inclusion

\begin{tabular}{|c|c|c|}
\hline Fixed operating conditions & $\begin{array}{l}\text { Variation of the mass ratio } \\
\mathrm{SC}-\mathrm{CO}_{2} / \text { physical mixture }\end{array}$ & $\% \mathrm{KP}$ complexed \\
\hline \multirow{3}{*}{$\begin{array}{l}\text { Maturation at } 338.2 \mathrm{~K} \text {, } \\
15 \mathrm{MPa} \text { during } 2 \mathrm{~h} \text { and a } \\
\text { molar ratio } \mathrm{KP} / \beta-\mathrm{CD}=1: 2\end{array}$} & 148 & 56.2 \\
\hline & 69 & 57 \\
\hline & 37 & 93.3 \\
\hline
\end{tabular}

both pilots. The autoclave volumes of the first and the second pilot are 2 and $0.5 \mathrm{~L}$, respectively. Two experiments were made in the first pilot by varying the mass of the physical mixture of 7 and $15 \mathrm{~g}$. We carried out an experiment in the second pilot with $7 \mathrm{~g}$ of physical mixture. The results are summarized in Table 4 . The percentage of complexation seemed to increase when the mass ratio $\mathrm{SC}-\mathrm{CO}_{2} /$ mixture decreased. Hence, for the same density of $\mathrm{SC}-\mathrm{CO}_{2}$ and similar experimental conditions, at the end of the experiment, the total quantity of $\mathrm{KP}$, which remained solubilized in $\mathrm{SC}-\mathrm{CO}_{2}$, was more important in the larger autoclave than in the smaller one. Thus the quantity included in CDs was more important in the smaller autoclave than in the larger one. Therefore, for small quantities of the physical mixture, it is more efficient to use not too great a quantity of $\mathrm{SC}-\mathrm{CO}_{2}$, so as to minimize the diluting effect of SC-CO .

\subsubsection{Method of preparation of the physical mixture}

To find out if there is an influence of the method of preparation of the mixture on complexation, we prepared mixtures by two different methods. In the first case, we mixed CD with KP and then added water and mixed all compounds together. In the second case, we mixed CD with water and then added KP and mixed a second time. Then, we studied the effects of pressure, temperature and duration of maturation.

Table 5 shows that, by adding water after KP, increasing the pressure and the temperature increased complexation. By adding water before $\mathrm{KP}$, the results of the complexation show that, at $338.2 \mathrm{~K}$, the pressure did not have any effect on complexation. However, at $348.2 \mathrm{~K}$, the increase in the pressure generated an increase in complexation, as for the first method. The addition of water before KP seemed to make the water structured in a more stable way on the CDs surface and in the cavities of CDs. It is more difficult to destabilize the water structured into the $\mathrm{CD}$ cavities to allow substitution by KP. At higher temperatures, here $348.2 \mathrm{~K}$, water in the cavities became less stable, and thus more likely to leave the cavities and to be replaced by KP. The increase of pressure enhanced the solubility of KP. The higher

Table 5

Influence of preparation method of the physical mixture on inclusion

\begin{tabular}{|c|c|c|c|c|}
\hline Fixed operating conditions & Pressure (MPa) & Temperature $(\mathrm{K})$ & $\begin{array}{l}\mathrm{H}_{2} \mathrm{O} \text { before } \mathrm{KP} \% \\
\text { complexed KP }\end{array}$ & $\begin{array}{l}\mathrm{H}_{2} \mathrm{O} \text { after } \mathrm{KP} \% \\
\text { complexed KP }\end{array}$ \\
\hline \multirow[t]{4}{*}{ Maturation during $2 \mathrm{~h}$ and a molar ratio $\mathrm{KP} / \beta-\mathrm{CD}=1: 2$} & 15 & 338.2 & 49.2 & 56.2 \\
\hline & & 348.2 & 51.2 & 65.6 \\
\hline & 20 & 338.2 & 50.5 & 65.2 \\
\hline & & 348.2 & 60.4 & 74 \\
\hline
\end{tabular}




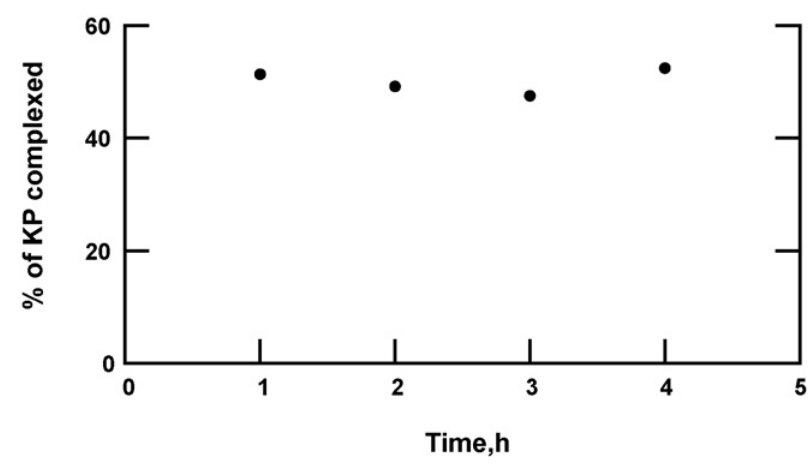

Fig. 11. Evolution of the amount of complexed KP with the duration of maturation (water added before ketoprofen).

temperature will then enhance the destabilization of the internal water and then allow the pressure on the complexation process to be more effective.

When water was added after KP, increasing maturation duration enhanced complexation (Fig. 9), but when water was added before KP, the duration of maturation did not have an effect on complexation (Fig. 11). When water was added before KP, the water molecules probably reached progressively a more stable energy state at the time of maturation and the contact surfaces of $\mathrm{CDs}$ with KP decreased. By reaching certain duration of maturation, the water molecules were probably in a stable weak energy state. Thus, there was less possibility for the water molecules to be replaced by the molecules of KP and beyond $1 \mathrm{~h}$, there was no replacement of the water molecules by those of KP. Moreover hydrophobic KP was poorly distributed onto $\mathrm{CD}$ surfaces when water was added before KP. Added water probably prevented $\mathrm{KP}$ from distributing homogeneously onto CD surface.

\subsubsection{Comparison of results with the literature}

Results found for the effect of the temperature were similar with those found by Van Hees et al. [1] on the complexation of Piroxicam into $\beta-\mathrm{CD}$ and Lochard et al. [14] on the complexation of Eflucimibe into $\beta-C D$. It may be noted that our team found a negative effect of the pressure on the complexation of Eflucimibe into $\beta-\mathrm{CD}$ using the same process [29]. This result is not in conflict with the present ones and may be explained by the Le Chatelier law, as discussed below. The similarity of our results with those found in reference [29] on the effect of the duration of maturation and the amount of water on complexation is noted. The complexation stoichiometry of $\mathrm{KP}$ into $\beta-\mathrm{CD}$ in the supercritical medium found here is the same as found in an aqueous medium by Marini et al. [30]. Yet, Mura et al. [28] indicated the formation of 1:1 complexes when they co-lyophilized a KP/ $\beta$-CD 1:1 molar mixture. Bruni et al. [31] reported experiments where they formed $\mathrm{KP} / \beta-\mathrm{CD}$ complexes by co-precipitation from an aqueous solution or by a water vapour equilibrated reaction. They found that the mole ratio of the complex differed depending on the initial mole ratio of the physical mixture. If the ratio was greater or equal to $3: 1$, they found a 1.15:1 complex; otherwise, they found a 1:2 complex [31]. Complexation is not strictly a chemical reaction that gives rise to a new true chemical compound. A complex is not formed with covalent bonds but with physical ones, which may explain that the stoichiometry is not so well defined. The literature has very few results on the effect of the agitation, the mass ratio $\mathrm{SC}-\mathrm{CO}_{2} /$ mixture and the method of preparation of the physical mixture. It seems that these parameters have not yet been widely studied.

\section{Further discussion}

We noted in our study that the formation of the association complex of KP into $\beta$-CD requires addition of water to the physical mixture. Water partially solubilizes the surface of $\beta-C D$ and induces cracks in the powder thus increasing their contact surface and this probably destabilizes water already present in the cavities of CDs. An attempt was made to analyse the nature of the water adsorbed onto $\beta$-CD by quantification of heat of dehydration on DSC thermograms. Dehydration occurred around $353.2 \mathrm{~K}$ and was complete below 368.2-373.2 K. It was found that, for the wetted physical mixture before maturation, the heat of dehydration was $2849.73 \mathrm{~J} / \mathrm{g}_{\text {water }}$ for the $\beta-\mathrm{CD}$ alone and was $2338.34 \mathrm{~J} / \mathrm{g}_{\text {water }}$ for the complex with a complex ratio of $95.5 \%$. In addition, the heat of evaporation of free water at $353.2 \mathrm{~K}$ was about $2311 \mathrm{~J} / \mathrm{g}_{\mathrm{water}}$. These results imply a heat of desorption of $538 \mathrm{~J} / \mathrm{g}_{\text {water }}$ or $9.6 \mathrm{~kJ} / \mathrm{mol}_{\text {water }}$ for $\beta-\mathrm{CD}$ alone and $27 \mathrm{~J} / \mathrm{g}_{\mathrm{water}}$ or $0.5 \mathrm{~kJ} / \mathrm{mol}_{\text {water }}$ for the complex. The value of $9.6 \mathrm{~kJ} / \mathrm{mol}_{\text {water }}$ for $\beta-\mathrm{CD}$ alone was consistent with the value of $10.5 \mathrm{~kJ} / \mathrm{mol}_{\text {water }}$ given by Bilal et al. [32] for solvation heat of $\beta-\mathrm{CD}$. Hence, the water remaining in the complex was weakly adsorbed. The water more strongly adsorbed onto $\beta-C D$ was probably destabilized and may have undergone change in its interactions with $\beta$-CD configuration during the maturation process. In addition, coulometer measurements were used to quantify the water adsorbed onto $\beta-\mathrm{CD}$ alone and onto the $95.5 \%$ complex. The amount of water found was 9.96 and $9.99 \mathrm{~mol}_{\text {water }} / \mathrm{mol}_{\mathrm{CD}}$, respectively. This would mean that all the added water, that corresponded to $2.41 \mathrm{~mol}_{\mathrm{water}} / \mathrm{mol}_{\mathrm{CD}}$ in reference experiment 1 took part in the maturation process, but extra water did not remain in the complex afterwards.

As for the role played by $\mathrm{CO}_{2}$ and considering the solubilities of the materials used, it is known that part of the water and KP solubilizes into $\mathrm{SC}-\mathrm{CO}_{2}[20,24]$. This solubilization is favoured by an increase in $\mathrm{CO}_{2}$ density and allows transfer of these molecular species throughout $\mathrm{CO}_{2}$ medium. The use of great quantities of $\mathrm{SC}-\mathrm{CO}_{2}$ also involves some dilution of $\mathrm{KP}$ in $\mathrm{SC}-\mathrm{CO}_{2}$, thus the reduction of the quantity included in CDs. Hence, $\mathrm{CO}_{2}$ has to be present to act as a transfer medium and the dilution effect has to be minimized. Introduction of agitation probably enhances mass transfer. Note that mass transfer also occurs throughout the dissolved $\beta-C D$ in water layer on the $C D$ surfaces.

$\mathrm{CO}_{2}$ acts also mainly through its pressure effect on complexation equilibrium. The Le Chatelier principle may be used to analyze this effect, as given for instance by Hoenigman and Evans [33]:

$\Delta V=-R T\left(\frac{\partial K}{\partial P}\right)_{T}+\Delta n R T K_{T}$ 
where $K$ is the equilibrium constant, $\Delta V$ the difference of molecular volumes of the products and the reagents, $\Delta n$ the difference of the stoichiometric coefficients of the products and the reagents, $T$ the temperature of the system, $P$ the pressure of system and $K_{\mathrm{T}}$ is the isothermal compressibility of the solvent.

For isothermal increase of the pressure, the equilibrium shifts as a function of the sign of $\Delta n$ and $\Delta V$. In the case here a KP molecule is included into two $\mathrm{CD}$ molecules. Therefore, the difference of the stoichiometric coefficients gives $\Delta n=1-(1+2)=-2$. The experimental results (Fig. 7) show that an isothermal increase of pressure favours complexation. Hence the term $(-R T(\partial K / \partial P) T)$ is negative and $\Delta V$ has to be negative. The $\Delta V$ is commonly described [34] as the sum of the difference of the molar volume of the products and the reagents $(\Delta V)$ and it is described as the sum of four volumetric contributions described in the Eq. (3):

$\Delta V=\Delta V_{\text {inclus }}+\Delta V_{\text {dissolv }}+\Delta V_{\text {cavit }}+\Delta V_{\text {conf }}$

where $\Delta V_{\text {inclus }}$ is the reduction in volume that accompanies complexation of KP into $\beta-\mathrm{CD} ; \Delta V_{\text {dissolv }}$ the volumetric variation, which accompanies the non-desolvation of included KP; KP is the hydrophobic, thus this variation may be negligible. However, some solvation of $\mathrm{KP}$ by SC- $\mathrm{CO}_{2}$ may occur, but could not be taken into account; $\Delta V_{\text {cavit }}$ the variation of the volume that accompanies expulsion of the water molecules of the cavity of $\mathrm{CD} ; \Delta V_{\text {conf }}$ is the increase in the volume that accompanies the change in conformation of $\mathrm{CD}$.

An attempt to estimate the overall $\Delta V$ by measuring the bulk densities of KP alone, of $\beta-\mathrm{CD}$ alone and of the $95.5 \%$ complex, was made with a helium pycnometer. Knowing each molecular weight allows conversion of the density measured into molecular volume. This gave 197.3, 776.7 and $1669.7 \mathrm{~cm}^{3} / \mathrm{mol}$, respec- tively, which gave $\Delta V=-81.1 \mathrm{~cm}^{3} / \mathrm{mol}$. The result is consistent with the above considerations deduced from Le Chatelier law.

Consider now the effect of the mixture preparation method. The method of preparation of the physical mixture is of capital importance. The addition of water before KP may structure the water molecules in a more stable state in the cavities of CDs. This slows down their substitution by the KP molecules. It may be then necessary to use a higher temperature to activate these water molecules, so they can leave the cavities of CDs to be replaced by the molecules of the active substances. Thus, it is more efficient to add water after KP. These considerations support the hypothesis that the mixture preparation method has to be made and performed in a very careful manner.

Summing up all the effects presented suggests three main phenomena involved. These may be an "external" transfer of molecular species (KP and water) through $\mathrm{SC}-\mathrm{CO}_{2}$, an "internal" transfer into CD interstices and through a partially dissolved $\mathrm{CD}$ layer at the $\mathrm{CD}$ surface, and a complexation reaction. All the parameters affecting these three phenomena are summarized in Table 6.

Finally, the recrystallization phenomenon must be considered. Once the wetted powder mixture has been put into the high-pressure autoclave, part of the water solubilizes into SC$\mathrm{CO}_{2}$. This induces the dissolved layer on the $\mathrm{CD}$ surface to be supersaturated. The entire system inside the autoclave is at constant temperature and pressure and will tend to evolve to minimize its free enthalpy. This recrystallization could then be driven by the minimization of the contact surface [35] and the cracks induced by the previous wetting of $\mathrm{CD}$ would tend to disappear, which has been discussed in a previous work [28].

Table 6

Effect of parameters on the kinetic of complexation and on the transfer into $\mathrm{SC}-\mathrm{CO}_{2}$ and $\mathrm{CD}$ surface and interstices

\begin{tabular}{|c|c|c|c|}
\hline \multirow{2}{*}{$\begin{array}{l}\text { An increase in parameter } X \text { has } \\
\text { the following effect on }\end{array}$} & \multicolumn{3}{|l|}{ Parameters $(X)$} \\
\hline & Transfer in $\mathrm{SC}-\mathrm{CO}_{2}$ & Transfer onto CD surfaces & Kinetics of complexation \\
\hline Temperature $(T)$ & $\begin{array}{l}\text { Positive effect on mass } \\
\text { transfer coefficient but lowers } \\
\mathrm{KP} \text { concentration in } \mathrm{SC}-\mathrm{CO}_{2}\end{array}$ & $\begin{array}{l}\text { Increase of the diffusivity into the } \\
\mathrm{CD} \text { interstices and through the water } \\
\text { on the CD surface }\end{array}$ & $\begin{array}{l}\text { Increase in the kinetic rate constant, positive } \\
\text { effect on complexation }\end{array}$ \\
\hline Pressure $(P)$ & $\begin{array}{l}\text { Negative effect on transfer } \\
\text { coefficient }\left(\mathrm{CO}_{2} \text { diffusivity }\right. \\
\text { and density increase })\end{array}$ & & $\begin{array}{l}\text { Increase of the equilibrium constant (cf. } \\
\text { comments on Le Chatelier law) }\end{array}$ \\
\hline Time $(t)$ & & & $\begin{array}{l}\text { Concentration of KP onto the surface of the CD } \\
\text { decrease and KP-occupied CD cavities increase. }\end{array}$ \\
\hline Agitation $(N)$ & $\begin{array}{l}\text { Improves transfer coefficient } \\
\text { and the homogeneity of the } \\
\text { mixture }\end{array}$ & & $\begin{array}{l}\text { So, assuming an equilibrium reaction, the } \\
\text { reaction rate decreases }\end{array}$ \\
\hline Amount of added water ( $\%)$ & & & $\begin{array}{l}\text { Would increase the dissolved layer onto the CD } \\
\text { surface, so the contact surface with KP. May } \\
\text { enhance the destabilization of absorbed water }\end{array}$ \\
\hline $\begin{array}{l}\text { Mass ratio } \mathrm{SC}-\mathrm{CO}_{2} / \text { physical } \\
\text { mixture }\end{array}$ & $\begin{array}{l}\text { Increase of } \mathrm{KP} \text { quantity } \\
\text { dissolved in } \mathrm{SC}-\mathrm{CO}_{2} \text {, } \\
\text { increasing its diluting effect }\end{array}$ & & \\
\hline $\begin{array}{l}\text { Mixture preparation: water added } \\
\text { onto } \mathrm{CD} \text { before } \mathrm{KP}\end{array}$ & & & $\begin{array}{l}\text { May increase activation energy of the } \\
\text { complexation reaction. May decrease the contact } \\
\text { surface KP/CD due to the poor distribution of } \\
\text { KP onto CD surface }\end{array}$ \\
\hline
\end{tabular}




\section{Conclusions}

The work presented here shows that KP can be complexed into $\beta-C D$ in supercritical medium using a batch supercritical fluid process. The process of maturation involves putting into contact the active drug, the $\mathrm{CD}$ and a certain quantity of water, in supercritical medium, over a certain period, to obtain an association complex. It proves to be a very promising process, since it is possible to obtain high percentages of complexation, without leaving any trace of solvents. Furthermore, it is a "green" process, as the method uses no organic solvent.

The parameters studied are divided into two categories, those related to the process; pressure, temperature, duration of maturation, agitation and the density of $\mathrm{SC}-\mathrm{CO}_{2}$ and those related to the physical mixture; amount of water, mole ratio KP/CD and the mass ratio $\mathrm{SC}-\mathrm{CO}_{2} /$ mixture. The influence of the method of preparation of the physical mixture on complexation has also been studied.

The increasing temperature acts on complexation increasing kinetics. According to the Le Chatelier principle and pressurevarying experimental results, an increase in the pressure moves equilibrium to favour the formation of a complex. The increase in the time of contact between the physical mixture and $\mathrm{SC}-\mathrm{CO}_{2}$ is favourable to complexation. This effect is very strong up to $2 \mathrm{~h}$ of maturation but weakens for times beyond $2 \mathrm{~h}$. The increase of the $\mathrm{SC}-\mathrm{CO}_{2}$ density allows increasing its solvation properties thus enhancing mass transfer. Agitation favours mass transfer in $\mathrm{CO}_{2}$. The addition of water to the physical mixture is essential for complexation. The water added to the physical mixture allows solubilizing the surface of $\beta-C D$ promoting surface cracking and increasing the surface of contact. It also destabilizes water present in the cavities of CDs making it unstable inside CDs and tending to evolve towards a more stable energy state by leaving the cavities of CDs, and being replaced by KP. The stoichiometry of complexation of KP into $\beta-\mathrm{CD}$ has been found to be $1: 2$, i.e. one KP molecule is complexed with two molecules of $\beta-\mathrm{CD}$. The use of great volumes of $\mathrm{CO}_{2}$ causes the dilution of $\mathrm{KP}$ in $\mathrm{SC}$ $\mathrm{CO}_{2}$, which decreases the quantity included in CDs. Therefore, a high powder density in the autoclave favours complexation. Finally, it can be concluded that the initial physical mixture must be carefully prepared by introducing water only at the end of the mixing procedure, and that conditions of temperature, ambient humidity and stirring have to be controlled.

This work confirms that the batch maturing process using supercritical $\mathrm{CO}_{2}$ is an effective and straightforward process of encapsulation by CDs. However, the phenomena in play are not so simple and need to be further investigated; for instance, the role of the added water has not yet been totally elucidated. Furthermore, to complete the present work some dissolution and stability studies on the complexed powder need to be performed.

\section{References}

[1] T. Van Hees, G. Piel, B. Evrard, X. Otte, L. Thunus, L. Delattre, Application of supercritical carbon dioxide for the preparation of a piroxicam $\beta$-cyclodextrin inclusion compound, Pharm. Res. 16 (1999) 1864-1870.
[2] T. Van Hees, G. Piel, S. Henry de Hassoville, B. Evrard, L. Delattre, Determination of the free/included piroxicam ratio in cyclodextrin complexes: comparison between UV spectrophotometry and differential scanning calorimetry, Eur. J. Pharm. Sci. 15 (2002) 347-353.

[3] M. Charoenchaitrakool, F. Dehghani, N.R. Foster, Utilization of supercritical carbon dioxide for complex formation of ibuprofen and methyl-/ $\beta$-cyclodextrin, Int. J. Pharm. 239 (2002) 103-112.

[4] B. Castel, Mise en forme des solides, Techniques de l'Ingénieur, Aspect théoriques [J 3 380], Génie des procédés, 1995.

[5] P.R. Vavia, P.T. Tayade, Inclusion complexation of ketoprofen with $\beta$ cyclodextrins, Indian J. Pharma. Sci. 61 (2) (1999) 97-99.

[6] J. Fages, H. Lochard, E. Rodier, J.-J. Letourneau, M. Sauceau, La génération des solides divisés par fluides supercritiques, Can. J. Chem. Eng. 81 (2003) 161-175.

[7] P.G. Debenedetti, J.W. Tom, X. Kwauk, S.D. Yeo, Rapid expansion of supercritical solutions (RESS): fundamentals and applications, Fluid Phase Equilib. 82 (1993) 303-310.

[8] E. Reverchon, Review: supercritical antisolvent precipitation of micro- and nano-particles, J. Supercrit. Fluids 15 (1999) 1.

[9] E. Weidner, Z. Knez, Z. Novak, PGSS (particles from gas saturated solutions) - a new process for powder generation, in: Proceedings of the Third International Symposium on Supercritical Fluids, Strasbourg, 1994, p. 229.

[10] M. Bahrami, S. Ranjbarian, Production of micro- and nano-composite particles by supercritical carbon dioxide, J. Supercrit. Fluids 40 (2007) 263-283.

[11] N.R. Foster, R. Mammucari, F. Dehghari, Coprecipitation of pharmaceuticals using gas antisolvent technique, in: Proceeding of the Eighth Meeting on Supercritical Fluids, Bordeaux, France, Tome I, 2002, pp. 321-326.

[12] V. Barillaro, G. Piel, S. Bertholet, S. Henry de Hassonville, B. Evrard, L. Delattre, Inclusion of miconazole into cyclodextrins by means of supercritical carbon dioxide: influence of the addition of an acidic ternary compound, in: Proceedings of the Sixth International Symposium on Supercritical Fluids, Versailles, 2003, p. 1897.

[13] B. Marongiu, A. Piras, S. Porcedda, A. Lai, S. Lai, Preparation and characterization of Imazadil/( $\beta$-cyclodextrin inclusion complex by supercritical carbon dioxide and ${ }^{13} \mathrm{C} \mathrm{Cp}$-Mas and ${ }^{1} \mathrm{H}$ NMR spectroscopy: preliminary results, in: Proceedings of the Sixth International Symposium on Supercritical Fluids, Versailles, 2003, p. 1903.

[14] H. Lochard, E. Rodier, M. Sauceau, J.-J. Letourneau, B. Freiss, C. JoussotDubien, J. Fages, A three step supercritical process to improve the dissolution rate of eflucimibe, in: Proceedings of the Sixth International Symposium on Supercritical Fluids, Versailles, 2003, p. 1659.

[15] D. Duchêne, B. Debruères, A. Brétillon, Les cyclodextrines, nature origine et intérêt en pharmacie galénique, Labo-Pharma Prolab. Tech. 32 (1984) 842-849.

[16] J. Szejtli, Introduction and general overview of cyclodextrin chemistry, Chem. Rev. 98 (1998) 1743-1754.

[17] H. Arima, H. Adachi, T. Irie, K. Uekama, J. Pitha, Enhancement of the anti-inflammatory effect of ethyl 4-biphenyllacetate in ointment by $\beta$ cyclodextrin derivatives: increased absorption and localized activations of the prodrug in rats, Pharm. Res. 7 (1990) 1152-1156.

[18] D. Amdidouche, P. Montassier, M.-C. Poelman, D. Duchêne, Evaluation by laser Doppler velocimetry of the attenuation of tretinoin induced skin irritation by $\beta$-cyclodextrin complexation, Int. J. Pharm. 111 (1994) 111116.

[19] S.-Z. Lin, D. Woessidjewe, M.-C. Poelman, D. Duchêne, In vivo evaluation of indomethacin/cyclodextrin complexes, gastrointestinal tolerance and dermal anti-inflammatory activity, Int. J. Pharm. 106 (1994) 63-67.

[20] S.J. Macnaughton, I. Kikic, N.R. Foster, P. Alessi, A. Cortisi, I. Colombo, Solubility of anti-inflammatory drugs in supercritical carbon dioxide, J. Chem. Eng. Data 41 (1996) 1083-1086.

[21] P. Mura, G.P. Bettinetti, A. Manderioli, M.T. Faucci, G. Bramanti, M. Sorrenti, Interaction of ketoprofen and ibuprofen with $\beta$-cyclodextrins in solution and in the solid state, Int. J. Pharm. 166 (1998) 189-203.

[22] A. Gil, Recherche de complexation entre une nouvelle entité chimique et des cyclodextrines par co-broyage et malaxage, Thèse de doctorat de l'université de Paris VI, 2001. 
[23] K.-H. Fromming, J. Szejtli, in: J.E.D. Davies (Ed.), Cyclodextrins in Pharmacy, Kluwer Academic Publishers, Dordrecht, 1994, p. 224.

[24] E. Stahl, K.W. Quirin, D. Gerard, Dense gases for extraction and refining (M.R.F. Ashworth, Trans.), Springer and Verlag, New York, 1988.

[25] D.-Y. Peng, D. Robinson, A new two constant equation of state, Ind. Eng. Chem. Fundam. 15 (1976) 59-64.

[26] P. Mura, A. Manderioli, G. Bramanti, S. Furlanetto, S. Pinzauti, Utilization of differencial scanning calorimetry as a screening technique to determine the compatibility of ketoprofen with excipients, Int. J. Pham. 119 (1995) 71-79.

[27] F. Giordano, C. Novak, J.R. Moyano, Thermal analysis of cyclodextrins and their inclusion compounds, Thermochim. Acta 380 (2001) 123-151.

[28] P. Mura, M.T. Fauci, P.L. Parrini, S. Furlanetto, S. Pinzauti, Influence of the preparation method on the physicochemical properties of ketoprofencyclodextrin binary systems, Int. J. Pharm. 179 (1999) 117-128.

[29] E. Rodier, H. Lochard, M. Sauceau, J.-J. Letourneau, B. Freiss, J. Fages, A three step supercritical process to improve the dissolution rate of eflucimibe, Eur. J. Pharm. Sci. 26 (2005) 184-193.
[30] A. Marini, V. Berbenni, G. Bruni, P. Mustarelli, Thermoanalytical and spectroscopic characterization of $\beta$ cyclodextrin/ketoprofen inclusion complexes, J. Inclus. Phen. Mol. Rec. Chem. 22 (1995) 221-234.

[31] G. Bruni, A. Marini, V. Berbenni, R. Riccardi, M. Villa, A novel method to obtain a $\beta$-cyclodextrin inclusion compound by solid state reaction: the ketoprofen case revisited, J. Inclusion Phenom. Macrocycl. Chem. 35 (1999) 517-530.

[32] M. Bilal, M. de Brauer, P. Claudy, P. Germain, J.M. Létoffé, $\beta$-Cyclodextrin hydration: a calorimetric and gravimetric study, Thermochem. Acta 249 (1995) 63-73.

[33] S.M. Hoenigman, C.E. Evans, Spectroscopic determination of pressure induced shifts in inclusion complexation equilibria, Anal. Chem. 69 (1997) 2136-2142.

[34] Y. Sueshi, N. Nishimura, K. Hirata, K. Kuwata, An ESR study of pressure effect on the inclusion complex formation of cyclodextrins with di-tertbutyl nitroxide, J. Phys. Chem. 95 (1991) 5359-5361.

[35] J.W. Mullin, Crystallization, third rev. ed., Butterworth-Heinemann, Oxford, 1992. 